\title{
El significante de la paz en el diálogo inter-religioso, una aproximación a los viajes inter-religiosos del Papa Francisco **
}

The significance of peace inside the inter-religious dialogue, an approximation to the Pope Francis inter-religious trips

O significante da paz no diálogo inter-religioso, uma aproximação às viagens inter-religiosas do Papa Francisco

\footnotetext{
${ }^{*}$ Licenciada en Sociología por la Universidad de Buenos Aires y maestranda en Estudios Sociales Latinoamericanos en la misma casa. Investigadora del Instituto de Estudios de América Latina y el Caribe (IEALC), integrante del UBACYT Nuevas derechas y democracias en América Latina (1980-2010) dirigido por Veronica Giordano y co-dirigido por Lorena Soler, del Grupo de Estudios sobre Estructuralismo y Postestructuralismo, y del Grupo de Estudios Estado, poder y alteridad en América Latina.. Correa electrónico: danarosenzvit@hotmail.com

${ }^{* *}$ Investigación realizada en el marco del seminario de investigación Sociedad y Religión. Metodologías cualitativas aplicadas al estudio de los fenómenos religiosos de la cátedra Forni/Malimacci de la Universidad de Buenos Aires, iniciado en marzo del 2014 y finalizado en mayo del 2015. Artículo de investigación recibido el 30/01/2016 y aceptado el 18/07/2016.
} 


\section{Cómo citar}

Rosenzvit, D. (2016). El significante de la paz en el diálogo interreligioso, una aproximación a los viajes inter-religiosos del Papa Francisco. Revista CS, no. 19, pp.39-67. Cali, Colombia: Facultad de Derecho y Ciencias Sociales, Universidad Icesi.

DOI: http://dx.doi.org/10.18046/recs.i19.2142 
El siguiente trabajo se propone analizar la manera en que funciona el significante de la paz en el diálogo inter-religioso y sus efectos en la construcción de hegemonía, a través de las acciones y declaraciones de los líderes de las tres religiones monoteístas de la Argentina. El artículo usa como referente empírico el viaje a Tierra Santa realizado por el Papa Francisco, el rabino Abraham Skorka y el dirigente islámico Omar Abboud y los encuentros inter-religiosos por ellos liderados. Con este objetivo, da cuenta de la realización y el análisis de entrevistas en profundidad a cinco dirigentes religiosos participantes en dichas actividades.

PALABRAS CLAVE:

Paz | dialogo | líderes | Papa Francisco | hegemonía

The following article analyses the function of the peace significant within the inter-religious dialogue and its effects in the construction of hegemony, through the actions and statements of the three Argentinean monotheist religions leaders. This article takes as its empirical referent the trip to Holy Land made by the Pope Francis, the rabbi Abraham Skorka and the Islamic leader Omar Abboud; as well as the inter-religious meetings led by them. With this purpose, To this end, it accounts for the implementation and analysis of in-depth interviews with five religious leaders participating in such activities.

\section{KEYWORDS:}

Peace | dialogue | leaders | Francisco the Pope | hegemony

O seguinte trabalho se propõe analisar a maneira em que funciona o significante da paz no diálogo inter-religioso e seus efeitos na construção de hegemonia, através das ações e declarações dos líderes das três religiões monoteístas da Argentina. Tomando como referente 
empírico na viagem à Terra Santa realizada pelo Papa Francisco, o rabino Abraham Skorka e o dirigente islâmico Omar Abboud e os encontros inter-religiosos por eles liderados. Com este objetivo, cumpre com a realização e a análise de entrevistas em profundidade a cinco dirigentes religiosos participantes nestas atividades.

PALAVRAS CHAVES:

Paz | Diálogo | Líderes | Papa Francisco | Hegemonia 


\section{Introducción y antecedentes}

En febrero de 2014 una comisión argentina, conformada por 15 referentes judíos, 15 referentes musulmanes y 15 referentes católicos, viajó a Tierra Santa. Al terminar el viaje se unieron en Roma con el Papa, quien anunció un próximo viaje con el mismo destino en el que sería acompañado por un rabino y un referente islámico, ambos elegidos por él. El 27 de mayo, luego de haber visitado la explanada de la mezquita, la tumba de Herztl, el muro que separa Israel de Palestina, entre otros sitios profundamente simbólicos, el Papa Francisco, el rabino Skorka y el profesor islámico Abboud, se abrazaban en el muro de los lamentos, mientras el primero decía a sus oídos "Lo logramos".

Tomando estos dos hechos, y sus repercusiones, como referente empírico, esta investigación aborda la siguiente pregunta: ¿Cómo funciona el significante de la paz en el diálogo inter-religioso, a través de las acciones y declaraciones de los líderes de las tres religiones monoteístas de la Argentina? Con el objetivo de responderla, el siguiente artículo presenta los antecedentes en torno a los procesos de pluralismo, fraternización y diálogo inter-religioso de las tres religiones monoteístas; seguido da cuenta del contexto conceptual y metodológico en el cual el trabajo se inscribe y presenta el referente empírico a estudiar, para posteriormente dedicarse al desarrollo y análisis del proceso en cuestión. Por último se presentan las conclusiones y los avances conseguidos.

Es preciso dar cuenta de los trabajos e investigaciones teóricas que abordan el proceso a analizar, mediante un recorrido por artículos y publicaciones dedicados a los procesos de pluralismo y fraternización que atraviesan las tres religiones monoteístas como respuesta a un marco global de secularización y crisis espiritual; así como por indagaciones producidas en torno a los procesos de diálogo inter-religioso. Por último, esta investigación aborda los trabajos que desde las ciencias sociales se dedican a la figura del Papa Francisco y a la coyuntura eclesiástica, internacional y nacional que funcionan como superficie de emergencia para su asunción y liderazgo. La actualidad del referente empírico en cuestión explica la falta de trabajos académicos en torno suyo, y la importancia de analizarlo ahora y aquí.

El trabajo de Garma (2011) estudia los procesos de racionalización, modernización y urbanización, y su relación con la herencia histórica de las creencias en lo sagrado; centrándose en la diversidad religiosa en Latinoamérica, y en especial en México, expresa su diferencia con el proceso que tuvo lugar en la Europa de la Reforma. Explica que en nuestra región las creencias religiosas se han sabido recuperar, y afirma los peligros de una interacción excesiva entre jerarquías eclesiales y la toma de decisión de los gobernantes (Garma, 2011: 88).

Morales y Lawrence (2011) estudian cómo, a través de la teología del pluralismo religioso, la Iglesia enfrenta los procesos de secularización y crisis espiritual. Tomando como punto de partida el Concilio Vaticano II, los autores explican que la teología del 
pluralismo religioso se postula en términos de posición, explicación y proposición, y no en términos de oposición y refutación; pasando así del enfrentamiento al diálogo y con el objetivo de llevar a la unidad trascendente, al centro común de las religiones que implica el encuentro inter-religioso (Morales y Lawrence, 2011: 88). Los autores hacen hincapié en que la apertura entre religiones no debe significar la disolución absoluta de los discursos, las experiencias y los meta-relatos, ya que una apertura hacia el infinito resultaría insostenible si se pretende dar valor y configurar una experiencia religiosa (Morales y Lawrence, 2011: 96).

El trabajo de Scobar Soriano (2006) se dedica, en el mismo sentido, a dar cuenta de los encuentros y documentos producidos por el Vaticano en torno al diálogo inter-religioso. Destaca el trabajo realizado por el Papa Juan Pablo II y explica que la Iglesia atribuye importancia central y creciente a la cuestión de las otras religiones. Concluye que el diálogo precisa de la propia identidad y del proceso inter comunicativo y relacional que se da a nivel humano y como parte de la misión evangelizadora de la Iglesia.

Las posibilidades de llevar a cabo esta misión, en un marco en que la diversidad religiosa se presenta para la Iglesia como un hecho y como un problema, son analizadas por Rogers (2012). En su trabajo dedicado a la doctrina de la Iglesia como sacramento universal, analiza el axioma extra ecclessiam nulla salus (fuera de la iglesia no hay salvación). Explica que es a través de la noción de la auto mediación mutua, que designa la importancia de los procesos de relación y comunicación para la conformación identitaria, que la Iglesia debe asumir el rol de salvación universal, entendiendo que existen diferentes fines religiosos que deben ser respetados y apreciados. La exhortación apostólica Evangelii gaudium redactada por el Papa Francisco en el año 2013, dedica una sección al "diálogo social como contribución a la paz", especialmente dirigido al diálogo inter-religioso. Demuestra la importancia que al tema se otorga al interior de la fe católica a partir de la declaración de Nostra Aetate.

Pace (2013) dedica su artículo a la crisis en la Iglesia católico romana frente a la cual asume su liderazgo el Papa Francisco. Con este objetivo comienza analizando el Concilio Vaticano II como respuesta a una crisis anterior en la misma institución. Explica que el Concilio Vaticano II representa un intento por conservar la forma romana de la iglesia, aceptando algunas presiones reformistas (247). Para el autor, la apertura al diálogo ecuménico es uno de los puntos centrales del Concilio. Aunque no es el diálogo ecuménico nuestro proceso particular de estudio, es fructífero considerar sus similitudes y alcances en cuanto a lo que aquí se analiza, y abordar los fundamentos del diálogo ecuménico, el autor incluye la relación con el Islam y el Judaísmo. Pace explica que el proceso de reunificación de la iglesia aspiraba a:

La inversión de un nuevo capital simbólico de la catolicidad por parte de la Iglesia misma. Tal inversión debía basarse en al menos tres fundamentales fuentes de sentido: El reco- 
nocimiento de las diferencias, un proyecto de reforma de la Iglesia católica, en la dirección del colegiado y de la apertura a la cultura moderna, y por último en la voluntad de renovar, y no solo actualizar, el sistema de forma de colocar a la Iglesia en permanente estado misionero, un misión ya no de conquista, sino de diálogo con las otras culturas y con el mundo moderno: un sistema organizado con confines simbólicos no pensados como muros defensivos, sino más bien como mamparas móviles, como un sistema cerrado para ser abierto, firme en sus principios pero atento a las razones del espíritu y de la verdad presente en otras religiones (Pace, 2013: 250).

Según Ulloa Rubke (2008) las condiciones para un diálogo son: autoafirmación, reconocimiento del otro, intercomunicación, siendo central para las religiones comprenderse mutuamente y cooperar en vistas a objetivos comunes (374). En esta misma línea, Corral y Petschen Verdaguer (2005) argumentan que el diálogo religioso y el diálogo cultural se exigen mutuamente en la búsqueda de la paz, intentando abatir muros históricos y seculares de ruptura y separación. Realiza un recorrido por Jornadas de la paz, tratados, declaraciones y conferencias en pos del encuentro y el pluralismo producidos por el Vaticano y por la ONU, analizando alcances, conflictos y dificultades. Utiliza el término "triágolo", para referirse al diálogo entre cristianos, judíos e islámicos, proceso que caracteriza fundamental y en crecimiento. En cuanto al contexto propicio para el diálogo, Alonso (2009) explica que este se da con la norma liberal, entre comunidades de fe diferentes que conviven en un espacio nacional (Alonso, 2009: 18); explica así que un entorno social de carácter extra-religioso funciona como condicionamiento del diálogo interreligioso (Alonso, 2009: 19).

Los trabajos de Gelabert Ballester (2008) y de Villar (2001) se dedican a la función religiosa de inspiración y promoción de la humanización, entienden que a través de ella se generan condiciones para el encuentro, y para un pluralismo que debe pasar de hecho a ser de derecho, basado en el reconocimiento de la pluralidad, que implica identidad propia y humanización compartida. Los autores argumentan que los valores a promover son universales pero particularmente anclados en la dimensión religiosa del hombre, y son necesarios para la edificación de la sociedad humana.

En cuanto a las articulaciones entre sociedad y religión, el trabajo producido por Mallimaci (2013), frente a la asunción de Bergoglio como Papa, presenta tensiones que es preciso tomar en cuenta. Comenzando con un racconto de las acciones y discursos del ex Arzobispo de Buenos Aires en el contexto nacional, entre las que destaca su liderazgo en el enfrentamiento político con el gobierno kirchnerista, el autor se pregunta por la función que el Papa Francisco cumple en la institución vaticana. Resalta la coyuntura internacional, en la que actos, gestos, palabras y mediaciones de un líder carismático son tomadas y expandidas por la prensa, otorgando a las autoridades religiosas una preponderancia global que perdieron en la política nacional. La unión 
entre el carisma personal de Bergoglio y el carisma de función de Francisco, ungen a los gestos y palabras del Papa de una autoridad que le permiten transformar las formas para mantener el contenido, dejando flotar significantes cristianos en el mismo sentido y dirección del actualmente dominante (237-238). Nos interesa en este sentido pensar el diálogo inter-religioso con judíos y musulmanes, tomado por el autor como un punto importante en la trayectoria nacional de Bergoglio, como un espacio para la puesta en acto de discursos y gestos producidos desde las autoridades religiosas, puestos en circulación por las corporaciones mediáticas y consumidos por laicos y religiosos en el contexto nacional e internacional, como respuesta a la coyuntura de violencia y transformación.

Los textos aquí reseñados nos dibujan una cartografía de los antecedentes teóricos de nuestra investigación. Nos permiten entender el campo en que nos inscribimos, y la necesidad de pensar desde la sociología los procesos que en el diálogo inter-religioso se articula.

\section{Marco teórico}

Para definir las religiones de salvación y las concepciones del mundo que implican, Marx Weber (1964) explica que las tres religiones abrahámicas - en las que este trabajo se centra- responden a un modelo de ascetismo intramundano. Weber establece que las religiones de salvación representan una forma de religión individualizada y usualmente privatizada, constituida por la relación personal con el salvador, que conducen potencialmente a la formación de comunidades religiosas universales a través de procesos de fraternización cada vez más amplios. La comunidad religiosa está determinada por el contenido y la estructura del propio mensaje religioso y por la dinámica de los intereses ideales y materiales de aquellos grupos y estratos a los cuales el mensaje religioso está originalmente dirigido. En este sentido cabe preguntarnos si el proceso que tiene lugar a través del diálogo inter-religioso, en el que se resaltan las características comunes a las tres religiones, puede ser visto como una fraternización que se acrecienta en cuanto se asemejan los contenidos y estructuras de los mensajes religiosos. Weber define a la doctrina metódica de salvación religiosa como una ética de virtuosos que en las tres religiones se establece a partir de un ascetismo intramundano que rechaza las tentaciones del mundo, pero no el obrar racional como tarea y medio de garantía de la gracia. Dado que la salvación debe ser universal, la relación personal con Dios se reviste de nuevas cualidades cuando comunidades pacíficas son portadoras de una religiosidad de salvación, de esta manera la fe adquiere su carácter emotivo al adoptar los rasgos del amor de dios. 
Max Weber plantea la noción de desencantamiento del Mundo para explicar los efectos de la modernidad industrial en cuanto a los fenómenos religiosos. En este marco las generaciones posteriores de sociólogos se enfrentan a la problemática de explicar el lugar que ocupa la religión en la coyuntura actual, signada por la racionalización y el proceso de secularización. En su texto La religión como sistema cultural, Geertz define a la religión:

[como un] sistema de símbolos que obran para establecer vigorosos, penetrantes y duraderos estados anímicos y motivaciones en los hombres, formulando concepciones de un orden general de existencia y revistiendo estas concepciones con una aureola de efectividad tal que los estados anímicos y motivaciones parezcan de un realismo único (Geertz, 1997: 89).

Como esquema cultural, la religión suministra programas para instituir los procesos sociales y psicológicos que modelan la conducta pública. A través de la aceptación de la autoridad que se encarna en el ritual mismo, la religión funciona como un modelo para y un modelo de, que otorga sentido y motiva a actuar de determinada manera. En cuanto al lugar social de la religión en nuestro siglo y en el siglo pasado, Casanova (1999) defiende que habiendo sido la fuente de legitimidad del orden social, en el Estado Moderno Secular es desplazada como marco de sentido, intrínsecamente ligada a la diferenciación histórica moderna entre las esferas pública y privada. En este espacio bisagra, la religión atraviesa una serie de transformaciones y vaivenes entre la relativización y desvalorización de este mundo hasta el lugar de compromiso con él, en que el individuo supramundano se convierte en el individuo intramundano (Casanova, 1999: 132-134). Cabe aclarar que aunque el autor se centra en la religión católica, los mismos procesos son análogos para las tres religiones de salvación monoteístas atravesadas por la tensión entre privatización y desprivatización. A través de este fenómeno las religiones vuelven a tomar su lugar en la sociedad civil con el objetivo de convertirse en garantes de la moralidad y la ética, en una disputa continua por su propia legitimización en este ámbito. En palabras de Ortiz (2005) las religiones buscan en la modernidad reconstruir su identidad a partir de un referente universal; en consecuencia, ética y moral son recuperados en términos mundializados. Es en este sentido que me interesa analizar el significante de la paz como espacio donde ética y moral se unen para permitir a la religión ocupar un lugar en la sociedad civil globalizada. Cabe en este punto retomar la definición de significante vacío elaborada por Laclau, en cuanto aparece como el lugar donde distintos significados se acolchan para obtener un sentido necesario y contingente.

Peter Berger (1968) afirma que en las sociedades modernas las religiones atraviesan un proceso de pérdida del monopolio de la definición de la realidad, cuyo efecto es el surgimiento y fortalecimiento de religiosidades privadas que se manifiestan como retórica 
pública y virtud privada. La dinámica global actual tiene su correlato en el pluralismo religioso, en cuanto a la estructura y al contenido del mensaje religioso, enmarcado en una situación de mercado en que distintas religiones participan como agencias mercantiles competitivas adaptadas a las preferencias del consumidor. Presenciamos entonces, según el autor, un proceso de burocratización que pone el cimiento social para la ecumenicidad en un estado creciente de colaboración amistosa. Kepel, en La revancha de Dios (1991), afirma que las instituciones religiosas se esforzaron por adaptar sus propósitos a los valores modernos de la sociedad. Según el autor, la década de 1970 fue el punto de inflexión de una descalificación global de la modernidad que permite a las tres religiosas abrahámicas criticar la incapacidad moderna para generar valores. En este sentido las tres se involucran en intentos de imponer sus propios valores y el vínculo religioso como fundamento del sistema social. Una estandarización religiosa que tiende a abolir las distancias entre las distintas confesiones. En palabras de Pierucci (1998) la pluralización religiosa no es solo resultado sino también factor del proceso de secularización creciente (129).

Habiendo llegado a este punto en donde se avistan ya los puntos en que se articulan las teorías y el suceso a analizar, se hace necesario distinguir a los agentes de las acciones, cuya intención se adjudica a la religión en sí misma. Sabiendo que esta es constituida por un grupo que detenta la autoridad o el carisma, y un grupo mayor de laicos, este trabajo se basará en las acciones y discursos de los referentes de las religiones en cuestión. Es ineludible analizar entonces, la cuestión de la autoridad en el campo religioso. Con este objetivo utilizaré los trabajos de Pierre Bourdieu y Saint Martin sobre el campo episcopal católico, entendiendo que sirven también como contexto conceptual para pensar el caso de la religión judía e islámica. El campo de poder religioso oficialmente instituido se inscribe él mismo en el centro del campo de poder simbólico de componente religioso (Bourdieu y Saint Martin, 2009: 119).

\footnotetext{
En él agentes con capital cultural suficiente como para pretender participar en las luchas simbólicas por la producción y la imposición de una visión del mundo y de una conducta de vida, convierten al campo en un campo de luchas dotado de una autonomía relativa con relación a las demandas de los laicos y capaz por este hecho de adelantárseles, y en cierta medida de producirlas. Se vuelven así los poderosos del campo, los privilegiados en tanto portavoces autorizados a tomar posición sobre las grandes cuestiones del momento (126). Así la competencia se da en el campo de la manipulación simbólica donde la lucha es por la capacidad de ejercer una acción simbólica, manipulando las visiones del mundo y la estructura de su percepción, así como los principios de construcción de la realidad social (Bourdieu, 1993).
}

Este poder simbólico se basa en la estructura jerárquica del campo, en donde la distribución desigual de las competencias religiosas aparece como evidente para los miembros que reconocen la autoridad de los poseedores y administradores del saber 
(Setton, 2002). A pesar de la perpetua lucha inherente al campo, la práctica estratégica de la lógica fundamental de la religión funciona como instrumento unitario y unificador en que el vocabulario del diálogo, de la fraternidad y de la convivialidad; no es una simple pantalla ideológica, sino la teoría adecuada del modo de funcionamiento y la visión del mundo social que constituyen a la iglesia misma (Bourdieu y Saint Martin, 2009: 139-143).

Teniendo en claro quiénes son los actores cuyas acciones y repercusiones esta investigación indaga, así como las motivaciones y procesos que detrás del diálogo inter-religioso se encarnan, ocupándose de lo que el conflicto en cuestión representa.

El significante de la paz se presenta como respuesta al conflicto árabe-israelí. En cuanto a lo que atañe a los estados de Israel y de Palestina, veremos, a partir de las nociones de Segato, el significado de este territorio para las confesiones en pugna. Por último y para analizar los clivajes en que se juegan los dos viajes inter religiosos a Tierra Santa se utilizan las nociones desarrolladas por Hervieu-Legér, cuando define a la religión como un modo particular de organización y funcionamiento del creer que se justifica reivindicando, ante todo, su inscripción en un linaje creyente, definiéndose objetiva y subjetivamente como una cadena de memoria cuya continuidad trasciende la historia (Hervieu-Legér, 2008: 39). Este factor aparece amenazado en las modernas sociedades que pierden la memoria social, dando lugar a una religión pos-tradicional que en vez de fundar las obligaciones del individuo en la tradición, condiciona dicho reconocimiento a la efectividad de su compromiso personal. Como la construcción de un grupo religioso entroncado a un linaje creyente se realiza según cuatro lógicas principales - comunitaria, emocional, ética y cultural-, la institución de lo religioso se define como el dispositivo social que garantiza la integración de estas cuatro lógicas alrededor de una tradición fundadora de autoridad. Según la autora esta función de integración falla en la modernidad, llevando a que las tensiones entre los polos devengan en líneas de fuga o generen crisis institucionales (Hervieu-Legér, 2000). La función del significante de la paz es abordada desde estas cuatro lógicas.

\section{Referente empírico y propuesta metodológica}

Con el objetivo de estudiar la función (o posición) que ocupa el significante de la paz al interior (o a través) de los procesos de diálogo inter-religioso, hemos elegido tomar como referente empírico a analizar el viaje a Tierra Santa realizado por el Papa Francisco, el rabino Abraham Skorka y el dirigente islámico Omar Abboud, en el año 2014. Realizado en el marco de un conjunto de acciones, gestos y discursos, llevados a cabo por Bergoglio, acompañado por autoridades religiosas judías, islámicas y católicas, en pos del diálogo inter-religioso y en respuesta al recrudecimiento de la violencia en Medio Oriente. El 
encuentro se inscribe en un proceso de ya larga duración a través del cual líderes de las tres religiones monoteístas han ido trabajando juntos en pro de la fraternización y el espíritu dialogal que postulan urgente y necesario en el mundo contemporáneo.

Este proceso podría pensarse en términos de continuidad con respecto al Concilio Vaticano II y a la posterior declaración Nostra Aetate. Entendemos que con este recorte pecamos de un católico-centrismo del que querríamos distanciarnos, más a la hora de observar el proceso en cuestión la institución del Vaticano aparece central e inamovible de la posición de liderazgo. Los encuentros de diálogo inter-religioso en Argentina, tienen también larga historia: su auge ocurre en la década de 1990, cuando bajo el liderazgo de autoridades religiosas hegemónicas se impulsó el crecimiento y empoderamiento de instancias compartidas en busca de mostrar a la sociedad los puntos de encuentro y cercanía. La formación del Instituto del Diálogo Inter-Religioso (IDI), alentada por Bergoglio y de la que fueron protagonistas sus actuales directores, Omar Abboud, Guillermo Marcó y Daniel Goldman, así como el programa de televisión que Bergoglio realizaba con Abraham Skorka, son hechos fundamentales a la hora de analizar las acciones que estos dirigentes llevan a cabo actualmente, con el mismo sentido y objetivo. Estos procesos en nuestro país estuvieron en consonancia con (y al interior de) los procesos globales, y todavía actuales, de neoliberalización, y privatización, y con sus consiguientes reversos de politización e irrupción de particularismos étnicos, raciales y religiosos, multiculturalismo transnacional y recrudecimiento de la violencia en todas las esferas de la vida occidental. En este sentido los encuentros de diálogo inter-religioso fueron nombrados por sus agentes como búsqueda y enseñanza de aceptación y no violencia. Desde el lugar de autoridad, los líderes religiosos respondieron a la coyuntura internacional pidiendo paz.

Con la asunción de Jorge Bergoglio, Arzobispo de Buenos Aires, como Papa, el "caso argentino" tomó relevancia internacional. Coherente con su trayectoria, sus acciones y discursos como figura máxima de la Iglesia Apostólica Romana privilegiaron el diálogo inter-religioso; en este sentido se ubicó en una trayectoria constituida por altas autoridades del Vaticano que comenzó con el Concilio Vaticano II y encontró su auge con el Espíritu de Asís en 1986, que discutida incansablemente por los teólogos ya es hegemónica y funcional a la institución en cuestión. Combinando ideas y hechos tradicionalmente papales, con innovación rioplantense, Bergoglio fusionó la función vaticana con la particularidad argentina, generando significaciones internacionales con respecto a una problemática económica y social que se dirime entre Israel y Palestina. En este sentido, pensamos que las prácticas y discursos expresados a través y en pos del diálogo inter-religioso deben ser explicadas tomando en cuenta las tensiones entre secularización/retorno a lo sagrado, y privatización/pluralismo religioso, que las religiones institucionalizadas de salvación atraviesan desde hace ya siete décadas. Queremos explorar la manera por la cual, en un marco de "desencantamiento del mundo" 
en palabras de Weber (1964), y de "pérdida del monopolio de la definición del mundo por parte de las religiones" según Berger (1968), las autoridades religiosas pretenden un rol privilegiado al interior de la crisis política internacional que representa el conflicto de Medio Oriente y el auge de particulares fundamentalismos religiosos. Con este objetivo estudiaremos las significaciones que se producen, utilizan y reproducen desde los discursos de los agentes religiosos que participaron en los viajes inter-religiosos realizados por el Papa Francisco1. Intentando responder a la pregunta sobre el funcionamiento del significante de la paz a través del diálogo inter-religioso llevado a cabo por autoridades religiosas argentinas, iremos en busca de los propios discursos de los agentes en cuestión, con el objetivo de explorar sus palabras y sus consiguientes acentos y significaciones.

El presente trabajo de investigación se llevó a cabo a través del análisis cualitativo utilizando la herramienta de entrevistas en profundidad. Durante 2015 se realizaron entrevistas a los cinco líderes religiosos argentinos participantes del conjunto de viajes realizados en pos del diálogo inter-religioso a Tierra Santa y a Ciudad Vaticano: el rabino Abraham Skorka, y el dirigente islámico Omar Abboud, autoridades escogidas especialmente por el Papa Francisco para el viaje a Tierra Santa. El primero es amigo y colega de Bergoglio, juntos escribieron un libro y realizaron un programa de televisión; y con el segundo, que es director del IDI, Bergoglio ha tenido relaciones desde el comienzo. El rabino Alejandro Avruj y el cura villero Pepe Di Paola, quienes hicieron un viaje a Tierra Santa y ciudad Vaticano en el marco de los viajes del Papa y con su apoyo y aval; y por último el cura Guillermo Marcó, antiguo colega de Bergoglio, quien fuera su portavoz en el Vaticano y quien también es director del IDI2. En todos los casos, los entrevistados consintieron ser grabados y nombrados para este trabajo. No hay que olvidar que tanto ellos como quien investiga somos constantes productores de discursos con intenciones particulares. En este sentido la doble hermenéutica juega un rol central, dado que las mismas entrevistas funcionan como discursos llevados a cabo por las autoridades religiosas en cuestión, puestos en circulación a través de esta investigación.

\footnotetext{
1. Nos centramos en el viaje realizado a Tierra Santa junto a Skorka y Abboud, pero teniendo en cuenta el antecedente del viaje, organizado por el IDI, de 45 argentinos: empresarios, políticos y autoridades religiosas pertenecientes al Judaísmo, al Catolicismo y al Islam. Es preciso tener en cuenta que meses después el Papa se encontraría en el Vaticano con el presidente de Israel y el presidente de la Autoridad Palestina. Es importante resaltar la analogía entre las acciones simbólicas realizadas con líderes religiosos y autoridades políticas: en el primer caso un abrazo fraterno; en el segundo, la siembra de un árbol.

2. Todas las entrevistas, excluyendo la de Omar Abboud, se realizaron en la institución de culto a la que pertenecen cada uno de los entrevistados, con el objetivo de situarnos en el mundo de la vida de los actores sociales en cuestión para entender los significados que estos dan a sus prácticas, gestos y discursos, y al contexto particular en que se llevan a cabo (Vasilachis de Gialdino, 2006: 31). Siguiendo a Geertz, intentamos inscribirnos al interior de una ciencia interpretativa que busca significaciones, para lograr una explicación que interprete las expresiones sociales, analizando lo dicho en el habla, la exteriorización intencional constitutiva de la finalidad del discurso (Geertz,1997: 20,31), preguntándonos por su sentido y su valor.
} 
Entendemos que nos encontramos en el registro de lo simbólico: la palabra, su sentido, y sus deslizamientos y significaciones sociales. Estudiaremos el discurso para explorar las posiciones que a través de él, se apropian, reapropian y conservan.

\section{Desarrollo}

\section{En torno al significante}

Laclau y Mouffe (2006: 142-143) explican que la identidad se constituye a través de la práctica de articulación, en un juego intermitente entre los momentos, entendidos como posiciones diferenciales al interior de un discurso, y los elementos, definidos como toda diferencia que no se articula discursivamente; frente al supuesto de que todo objeto es constituido como objeto de discurso, se hace posible la práctica articulatoria. La articulación, así como la contingencia, son posibles porque ninguna formación discursiva es una totalidad suturada y porque, en consecuencia, la fijación de los elementos en momentos no es nunca completa. Todo discurso, resultante de la práctica articulatoria de fijación resulta metafórico o metonímico. El discurso se constituye como intento por dominar el exceso de sentido que le es inherente, haciendo necesaria la práctica de la articulación para construir puntos nodales, puntos discursivos privilegiados, donde un sentido pueda ser fijado parcialmente a pesar de estar constantemente desbordado. El punto nodal, o significante vacío, es definido por los autores "como la palabra que como palabra, en el nivel del significante mismo, unifica un determinado campo, constituye su identidad", y su nombre genera la unidad de una formación discursiva (Laclau, 2005: 135). La condición necesaria para la aparición de la articulación hegemónica es el colapso de la línea demarcatoria entre lo interno y lo externo, siendo así que la hegemonía supone el carácter incompleto y abierto de lo social, un campo dominado por las prácticas articulatorias, surcado por antagonismos y por la inestabilidad de las fronteras que los separan. Dado que la totalidad es tanto imposible como necesaria, debe existir la posibilidad de que una diferencia, sin dejar de ser particular, asuma la representación de una totalidad inconmensurable consigo misma. Este proceso es denominado hegemonía por Laclau (2005), y es resultado de la investidura radical que se lleva a cabo haciendo de un objeto la encarnación de una plenitud mítica. La identidad hegemónica pasa a ser parte del orden del significante vacío y sin embargo, dado que el todo va a ser siempre encarnado por una parte, no existe universalidad que no sea universalidad hegemónica. De esta forma la hegemonía es definida como un tipo de relación política, que se impone a comienzos de los tiempos modernos, sólo posible en cuanto un conjunto de diferencias constituye una cadena de equivalencias, generando 
así una formación que se significa a sí misma a partir de la exclusión de lo que ella no es (Laclau y Mouffe, 2006: 188).

Los discursos producidos por los agentes religiosos que aquí analizamos, serán pensados al interior de una formación discursiva constituida a partir de la articulación hegemónica que precisa de un juego medido, pero siempre en peligro de desbordarse, entre equivalencia y diferencia. El éxito de los agentes para construir un discurso a través de sus posiciones relacionales, depende de la demarcación de una frontera con un afuera y de la fijación de puntos nodales significativos para asumir el lugar de la universalidad, de una encarnación mítica. Este espacio será ocupado por el significante de la paz, que como palabra unifica y constituye la formación discursiva producida y sostenida por los agentes religiosos de las tres religiones monoteístas argentinas en tanto práctica de articulación hegemónica.

\section{La familia abrahámica}

A través de prácticas, gestos y discursos, los agentes religiosos en cuestión dan cuenta de un proceso de fraternización creciente entre las tres religiones monoteístas (Weber, 1964). Frente a la misma coyuntura nacional e internacional, los líderes religiosos resaltan las características y orígenes en común, al interior de un juego entre equivalencia y diferencia que permite generar un lugar compartido de enunciación, cuidándose de no perder la propia particularidad. Frente a la pregunta por la definición de la religión de la que forman parte, resalta en las respuestas, lo compartido por las tres religiones, y la relación entre iguales y diferentes en que estas se encuentran frente a los procesos inter-religiosos.

"La palabra religión viene de relligare, es el hombre que busca a dios, la particularidad de las religiones del libro, o sea la judía, la católica, la musulmana es que nosotros creemos en que no solamente el hombre sale a la búsqueda de dios, sino que también dios sale a la búsqueda del hombre" (cura Guillermo Marcó).

"Más allá de los modos hay un punto en común en el origen, que hacen que al contrario, las diferencias a veces fortalecen. La experiencia de la religión cuando se vive con espíritu abierto, como la vivimos nosotros, hace que llegues a punto de coincidencia muy grande aun con gente que profesa otra. En vez de ser una fuerza que te cierre, es un espiritu que te abre (...) te das cuenta compartiendo con el judio que tenemos todo el antiguo testamento para compartir, tenemos demasiado para compartir, tenemos mucho de extraordinario en la manifestación de dios que compartimos" (padre Pepe Di Paola).

"La religión, para mí, debe ser el faro de ese equilibrio entre lo igualy lo diferente, la voz quenos recuerda que todos somosiguales hijos de dios, y por suerte todos diferentes, ese juego delicado 
y frágil de seriguales pero distintos exige equilibrioy creo que ese es el lugar de la religión, el del faro que equilibra, viendo al otro como un igual, encontrar a diosy sostener tu diferencia (...) Es todo lo mismo, somos todos iguales, para qué la división si el rabino habla divino de la paz y lee este texto, y el cura habla más divino y lee el mismo texto, para qué las divisiones, ¿para qué? Si somoshermanos, y ahídije "Para para para, no somos todosiguales, por suerte". Porque en la idea del diálogo y la igualdady el amor corremos el peligro de pensar que tenemos que ser todosigualesy en nombre de la igualdad nosperdemos el sello de la creación que es la diferencia. Nuestra diferencia es clave, importantísima" (rabino Alejandro Avruj).

"la religión se define por la fe, el cristianismo es una religión, para ser cristiano tienes que tener fe en Cristo, igual en el Islam, o en cualquier confesión religiosa. Para ser judio no tenés que tener fe en algo o en alguien, para ser judio, la definición dejudio, es aquel que nacejudio o que tiene un proceso de conversión a través del ingreso al pueblo, vos sos hijo de Abraham cuando te convertís, no sos creyente en dios, sos hijo de Abraham, todos somos hijos, cuando creces sos bar mitzva, esto tiene quever con una familia. El judaismo sobre todas las cosas es una familia (...) el cristianismo nació en el seno del judaísmo, Jesús era unjudio, hay que ver cómo calificar, como nombrar si es recrear un vínculo o crear uno nuevo, pero de todos modos ver cuáles son las metas comunes hacia donde quieren llegar los judios y hasta dónde quieren llegar los cristianos, y aunar esfuerzosy verse como hermanos realmente, en un principio hubo una cuestión de hermandad, entonces se debe recrear, yo creo que hubo un odio en un pasado entre judiosy cristianos porque el odio existe donde hay un sentimiento de cariño, un sentimiento de amor" (rabino Abraham Skorka).

"Yo, a esta altura de mi vida, veo un judio rezando, un católico rezando, yo sé lo que está haciendo, está haciendo lo mismo que yo, pero de otra manera. El grado de religión me da la idea de que lo mío es una certeza de la misma manera que es una certeza para él, la verdad la sabremos en la vida postrera o cuando venga el final de los tiempos en la cuestión profética" (dirigente islámico Omar Abboud).

Queremos destacar la repetición de los significantes "familia" y "hermanos" para referirse a la religión o a las relaciones con las demás religiones monoteístas; el hecho de que para definir la ropia religión se nombre a las otras dos o a alguna de ellas evidencia la tensión presente entre igualdad y diferencia entre las tres religiones abrahámicas. Según Berger (1968) y Pierucci (1998) la secularización presente en nuestras sociedades modernas tiene como correlato al pluralismo religioso, como estado de colaboración creciente entre las distintas religiones. Ya en respuesta a las razones y alcances de los procesos de diálogo inter-religioso, los entrevistados dan cuenta del pluralismo en cuestión, en tensión permanente entre identidad y diferencia.

"Como hombres religiosos que somos lo importante para míno es que enseñen que no hay que discriminar, me parece bárbaro, pero lo importante es la construcción colectiva que hacemos 
entre las religiones cuando nos juntamos, cuando nos unimos por un objetivo, cuando nos es grato encontrarnos (...) las grandes religiones tienden a buscar los grandes lineamientos comunes" (padre Pepe Di Paola).

"Lo que estamos proponiendo es una construcción mental, dialogar es una categoría en términos de la resolución del conflicto en que las reglas del juego tienen que ver con sentarte en esa mesay estarpermeable para modificar tu realidad o tu perspectiva, te tenés que sentar con esa cabeza, con la posibilidad de ser tocado en tu identidad blanda, en aquello que genera la relación" (dirigente islámico Omar Abboud).

Es posible dar cuenta de un proceso en el que desde el campo de poder religioso se impone una visión de la propia religión y de las otras religiones monoteístas, hermanadas y unidas. Utilizando la práctica estratégica de la lógica fundamental de la religión como instrumento unitario y unificador, así como diferenciado y diferenciador, permitiendo decir experiencias distintas en una misma lengua religiosa, en palabra de Bourdieu y Saint-Martin (2009: 143).

\section{Frente al año 5775, 1436 o 2015 años después de circuncidado Cristo}

Las religiones monoteístas transitan en nuestro Occidente moderno el proceso que Weber nombró como desencantamiento del mundo, que implica la pérdida del monopolio de la definición de la realidad por parte de las religiones (Berger, 1968); sin embargo, mantienen, en palabras de Bourdieu y Saint-Martin (2009) el monopolio de la representación legítima de su grupo y el poder simbólico que a través de esta se ejerce. Al interior de esta tensión las religiones atraviesan un proceso de relativización del mundo, así como de compromiso con este, que se manifiesta como retórica pública $\mathrm{y}$ virtud privada. Asistimos así a la aparición de religiones post-tradicionales, en las que las obligaciones de los individuos no surgen del origen postulado en la tradición, sino del compromiso personal de los creyentes (Hervieu- Léger, 2010). Frente a esta situación, explica Ortiz (2006), las religiones en la modernidad buscan reconstruir su identidad a partir de un referente universal, siendo ética y moral recuperados en términos mundializados. En este sentido, los agentes religiosos se dedican crecientemente a problemáticas políticas y sociales, según las demandas de los laicos y las posiciones de poder que a través de esta dinámica se pone en juego.

"En algún momento se decía que había que sacar la religión porque entorpecía la vida del ser humano,ynoshemosdado cuenta quelo que hacefalta esmásreligión” (padre Pepe DiPaola).

"La religión funciona como el sostén moral yético de la conducta ante los hombres, sí. No con el poder coercitivo que pudo tener en su momento porque ese poder se le ha delegado al estado, 
perosícomosalvaguarda de la ética, de la moraly del entendimiento. (...) Elmundono necesita menos religión para solucionar la guerra, necesita más religión” (rabino Alejandro Avruj).

"Fácilmente te podés dar cuenta que no existe (en el Islam) un rasgo distintivo entre lo que es seculary lo que es sagrado, es esta visión integrada (...) la religión islámica es un modificadory una presencia sustancial en cada uno de los aspectos de la vida" (dirigente islámico Omar Abboud).

"En el judaismo no hay una división, el fenómeno religioso per se, el fenómeno religioso per se tiene sus implicaciones en la vida diaria, en la Torá misma aparece leyes de derecho penal, derecho comercial, derecho de familia (...) El Judaismo como es tan antiguo es una cuestión cultural, la religión en el judaísmo es una cultura. Esto es así, brevemente. Si bien todos los judíos no son religiosos practicantes, pero de alguna manera la religión está muy conectada concatenada con pensamiento espirituales, actitudes espirituales, algo que tiene que ver con lo religioso (...) el judaísmo es una civilización, tiene todos esos aspectos, históricos, nacionales misticos, es una civilización, atravesó todos los tiempos, pero no es solo una religión" (rabino Abraham Skorka).

"Para mí el lugar de la religión tiene que ver con lo que cada persona profesa, en qué lugar tiene, para mílo que vos crees tiñe tu modo de mirar o debería influir en eso. Yo no miro igual si soy creyente o si no tengo fe, por eso me parece que influye, tener una carrera o una vocación particular es también un modo de mirar la vida (...) mi vida está teñida de eso porque forma parte de mi esencia, inseparable de mi modo de vivir (...) la fe es algo que usamos todos los días para todas las cosas sin darnos cuenta" (cura Guillermo Marcó).

En los discursos producidos por los agentes religiosos encontramos la insistencia en un continuum religioso en el orden de lo secular, que hace posible entender todos los aspectos de la vida pública y privada al interior de un grupo religioso, un linaje creyente, y una ética de virtuosos que constituye la religión. Desde el lugar de autoridades, los agentes se inscriben al interior de un ethos compartido, en que la religión aparece como indisociable de la coyuntura actual. Aun mostrándose conscientes del proceso de secularización que atravesó nuestra sociedad, los entrevistados se ocupan de ubicar a la religión en un lugar predominante y normativo en el día a día moderno y occidental. Con este objetivo los significantes ética y moral ocupan un lugar privilegiado en cuanto funciones religiosas; de la misma manera el "nosotros" que constituye a los hombres religiosos que defienden una ética de virtuosos, se verá conformado a partir de un efecto de frontera que deja afuera a un "ellos" habitado por los agentes políticos a quienes se les reclama la ineficacia para tratar con los problemas modernos en cuanto actores privados con intereses individuales.

"Las generaciones actuales han fallado en algunas cosas, uno puede tener esperanzas en que estos gestos cambien para el futuro y que haya otros que se sientan inspirados para vivir sin violencia. Obviamente que esto no es solo para afuera, es también para nosotros, para vivir 
juntos, respetar al otro como es. (...) En los últimos tiempos, sin duda que la religión católica tuvo un rol preponderante en cuanto a la construcción de la paz, a veces las potencias occidentales tienen un papel muy hipócrita en cuanto al tema de la paz (...) cuando vos los empujas con ejemplaridad el que queda como outsider es el que quiere otra cosa, entonces ¿ंquerés la paz o no querés la paz? Porque hay mucha mentira en el medio, si se quiere la paz, ¿por qué siguen construyendo asentamientos en zonas conflictivas? No parece quererse la paz" (cura Guillermo Marcó).

"Por un lado el líder religioso tiene la obligación desde el punto de vista bíblico de hablar sobre todos los temas, porque el judaísmo es una cultura donde lo religioso es el elemento fundante de esta cultura, el elemento donde a través de la Torá, donde hayamos todo tipo de normas me va regularizando los distintos aspectos de la vida, tenés que hablar acerca de educación y acerca de valores políticos pero no como un político, pero no como un político. (Haciendo mucho énfasis). El líder religioso tiene que hablar como hablaban losprofetas desde un estrado distinto, un estrado donde no hay compromisos, nicon ministros ni con presidentes nicon nadie, el único compromiso que hay es con la pureza del espiritu. En el caso de la política uno siempre está comprometido con, está en una lucha, por eso mi énfasis. (...) Basta ver la pobreza de los diálogos en el congreso, hasta ver la pobreza dialogal cuando hay dramas políticos, politicos de distintos partidos en la televisión. Cada uno puede hablar muy lindo, como un soliloquio pero no como un diálogo" (rabino Abraham Skorka).

"Elmundo es un mundo sin diálogo, no es un fenómeno político que existe solo en la Argentina porque tenemos una fractura, no, yo prefiero decir que entre nosotros tenemos una mirada mutilada, una mirada prejuiciosay demasiado pasional para los órdenes racionales que debemos resolver. La política es un lugar que obviamente incluyela pasión en cuanto alfervor pero como ciencia política su deber de resolución es racional (...) A míno me gusta la palabra ni modelo ni relato para hablar de politica (...) me parece que la sentencia unívoca "yo soy el camino" solo la puede decir Jesús, ningún otro, ¿entendés? Me parece que en ese aspecto tenemos que madurar y crecer, asi como yo te hable del plano metafísico, en algún momento tenemos que teorizar en torno a lo metapolítico, que tiene como fin obviamente el bien común y el respeto" (dirigente islámico Omar Abboud).

"La guerra ocupa un lugar anti-religioso. (....) Realmente esta violencia que se está viviendo es lo más antireligioso que hay, pero tiene queser denunciadoporclaridad porpartede todoslos capos religiosos del mundo (....) yo creo que la imagen que le quedó al mundo es que la mayoría quiere la paz, los líderes religiosos rezaronjuntos por la paz, el problema es politico, podemoshablar de explicaciones históricas, ancestrales, blablabla (gesticula) pero al menos desde el punto de vista de la fe creo que se puede ir fortaleciendo este espirituy por supuesto que necesita de una autocritica de todas las religiones, todos tenemos que pedir perdón, desde cosas que hicieron hermanos nuestros en el pasado, todos, nadie puede decir que es trigo limpio, pero es importante que se fortalezca el diálogo (...) yo veía que los politicossepeleaban entre todosyyo mejuntaba con Ale (Avruj), con Goldman, con el árabe que me traía la carne a los comedores, la que comían ellos. 
Nosotros vivíamos un mundo de compartirmientras quelospoliticossesacaban los ojos, yunose preguntaba ¿cómo no era al revés? No, porque acá estamos en lo esencialy con el espíritu abierto, este es el espíritu que tiene que imponerse. No lo hacemos por eso pero creo que la consecuencia es esa (un reclamo a las autoridades políticas)" (padre Pepe Di Paola).

La frontera construida a través de discursos que hablan sobre prácticas, permite la constitución de un "nosotros" habitado por las autoridades religiosas, productoras de esta misma frontera. En este sentido, a los intereses privados de los agentes políticos oponen los valores colectivos y la ética de virtuosos que ellos mismos profesan, y que les permite mantener una función preponderante al interior de la sociedad civil. Las autoridades religiosas detentan el capital cultural suficiente como para pretender participar en la producción e imposición de una visión del mundo y de una conducta de vida, convirtiéndose en portavoces autorizados a tomar posición sobre las grandes cuestiones del momento (Bourdieu, Saint Martin, 2009: 143), en nuestro caso sobre la guerra de Medio Oriente entre Israel y Palestina. A partir de la jerarquía institucional del campo religioso, las autoridades ocupan el lugar reconocido, de los portadores y administradores del saber (Setton, 2012). Es desde esta posición que los agentes enuncian, al interior de una dinámica institucional y social que les permite detentar el lugar del ejemplo a seguir.

"El shek es la persona que te orienta y también te enseña y te resuelve dudas muchas veces. (...) Nuestro desafío es ver cómo podríamos generar un espacio de traslado la sociedad en general (sobre el diálogo inter-religioso) (...) La paz no es simplemente la ausencia de guerra, del hecho bélico, la paz tiene toda una multiplicidad de connotaciones referidas, o centradas, y relacionada con los aspectos que te enumeréhace un rato en referencia al hombre consigo mismo, con los demás, con la naturaleza y con la divinidad, tiene que ver en términos de estado con una referencia a lo mental, al equilibrio relacionado al paraíso, en la tradición islámica la palabra que escuchas en el paraíso es solamente paz" (dirigente islámico Omar Abboud).

"La mejor traducción de rab, es maestro, docente (...) yo creo que la mayoría de las confesiones religiosas y la mayoría de sus adeptos, especialmente los que están involucrados en espacios de espiritualidad, de estudio, depensamiento, de contención comunitariay espiritual, lograntener esta concepción del mundo (en torno a la religión como soporte moraly de contención) (...) La mayoría de los religiosos de todas las religiones se dedican a hacer que la vida sea mejor, que la genteviva con mayor paz, con mayor encuentroy mayor amor al prójimo, perosenecesita mucho, mucho camino para recorrer, especialmente del encuentroy delospuentes de entendimiento entre las diferentes corrientes religiosas, entre todas las sociedades, no sólo las religiosas, el desconocimiento del otrolleva automáticamente a la discriminación" (rabino Alejandro Avruj).

“Cuando una persona tiene la grandeza en el corazón siente un placer enorme de poder compartir con alguien de una religión diferente (...) Cuando me refiero a que hace falta más religión 
me refiero al espírituy no a las deformaciones que tuvo, en eso creo que el diálogo inter-religioso es un buen ejemplo para toda la humanidad" (padre Pepe Di Paola).

"Esta guerra tiene aspectos religiosos, lo que es verdad, es verdad, y hay todo tipo de sentimientos, no es una guerra meramente por factores económicos o lo que fuere, hay aqui cierto componente religioso, el ideal bíblico es la paz, el ideal biblico es la paz, por un lado y por el otro va a haber que luchar para construir la paz, la paz se construye, hay que trabajar para ello. (...) Losjudios, los cristianosy los musulmanestenemos que tener un diálogo urgentemente para tratar de cambiar la problemática mundial de hoy en día. (...) Yo creo que la primer vía como para que Occidente o las distintas iglesias cristianas puedan dar un aporte por la paz, es entrando en diálogo con el mundo musulmán, con la intelectualidad con lo más granado del musulmán como para mostrar una y mil veces cuál es la real senda a través de la cual se puede llegar a solucionar los problemas de la vida, o los problemas comunes, o todo aquello que conlleva un choque, primero y antes que nada lo que debe hacerse es comenzar a forjar las bases de un proceso dialogal, porque eso no se hace de un día para el otro. En el momento en que puedan haber mesas redondas, donde judios, musulmanes y cristianos de la más alta representatividad puedan estar sentados hablando, tratando de entenderse el uno al otro, conocerse, en ese momento las cosas van a calmarse un poco más (...) Y luchamos juntos para crear esos puentes, ¿para quécrear esos puentes? Para poder llegar a trabajar juntos, primero reconciliarnos, y despuéspara poder llegar a trabajarjuntos en pro de una realidad donde haya más diálogo y más espiritualidad (...) y yo cuando hablaba, hablaba de todos los temas, pero desde el punto de vista, basándose en la biblia, basándose en el talmud, basándose en lo que el judaismo dice, yo quería contribuir a la cultura argentina amplía a través de la experiencia espiritual judía, ¿está claro?” (rabino Abraham Skorka).

"El Instituto del Diálogo Inter-religioso obviamente está a favor de la paz mundial, pero notiene ninguna pretensión de esas características. Nosotros estamos más definidos como luchadores en contra de la ignoranciay el prejuicio que luchadores a favor de la paz, sostenemosy creemos que justamente desde la ignorancia viene todo lo otro" (cura Guillermo Marcó).

El significante paz, actúa en (y a través de) los discursos de las autoridades religiosas, como un punto nodal que constituye la identidad misma de la formación articulada hegemónicamente a través del diálogo inter-religioso. Los sentidos producidos y puestos en circulación por los agentes religiosos a través de las instancias y procesos de diálogo inter-religioso escapan constantemente a la sutura necesaria para la definición, haciéndose necesaria la investidura radical del vocablo "paz" en el que se acolchan parcialmente los sentidos en cuestión, así como sus cargas ideológicas con efectos performativos. Al interior de esta formación, las posiciones relacionales de los agentes y los sentidos que en ellas se sostienen, funcionan a través de una dinámica entre equivalencia y diferencia que permite la construcción de un espacio compartido, a través de la constitución de una frontera con un afuera tanto necesario como contingente. Podemos observar en los dichos 
de nuestros entrevistados la marcada necesidad de distanciar esta guerra de sus posibles causas religiosas, marcando una fuerte distinción entre los intereses económicos y políticos que se ponen en juego a través de la guerra, y el espacio religioso en que se busca desinteresadamente la paz y el bienestar mundial. A través de la provocación de un ethos y de la definición de una imagen del orden cósmico por medio de una serie de símbolos, los líderes religiosos, buscan generar la representación necesaria para que dichos símbolos funcionen como "modelo para" y "modelo de", expresando para los fieles la atmósfera del mundo y modelándola, según la terminología de Geertz (1997: 100).

En este sentido, la paz como valor religioso es postulada por las autoridades religiosas como elemento ético y moral necesario y urgente para la coyuntura actual; al tiempo que ellos mismos se postulan como el ejemplo y el camino a seguir al interior de la sociedad civil moderna. Siguiendo a Kepel (1991) podemos decir que desde la religión se critica a las autoridades modernas por su incapacidad para producir y mantener valores, generando así una distancia a través de la cual se pretende ubicar a la religión en un lugar privilegiado para solucionar las crisis actuales. En el mismo movimiento se genera una estandarización de las religiones a partir de sus objetivos y discursos comunes que funcionan al interior de un pluralismo religioso que, según Berger (1968), implica una situación de mercado en la que las religiones se adaptan a las preferencias del consumidor, en este caso a los pedidos de paz y a la preocupación por la hipocresía de los agentes políticos frente al conflicto de Medio Oriente.

Siguiendo a Hervieu-Léger (2010) podemos entender, desde el registro ideológico y simbólico, los procesos de diálogo inter-religioso como una estrategia de los líderes religiosos para reconciliar y hacer funcionar en conjunto a las cuatro lógicas principales necesarias para la construcción de un grupo religioso como parte de un linaje creyente. Entendemos al uso del significante de la paz como una apuesta de las autoridades religiosas en pos de legitimación y continuidad de los procesos de socialización al interior de los marcos institucionales. El significante de la paz aparece como un lugar privilegiado en que puede darse la integración o la regularización de las tensiones entre las cuatro lógicas comunitarias alrededor de una tradición fundadora de autoridad. La paz, en su constante desbordamiento de sentido, puede funcionar como imperativo ético, valor universalizable compartido por el nosotros que el grupo conforma como norma de conducta; necesidad emocional para el "nosotros" que el grupo religioso significa; prioridad cultural como saber constituido en la memoria colectiva del grupo; y figura comunitaria, en cuanto buscar la paz aparece como ejemplo para quienes pertenecen al grupo religioso. De esta manera, el significante de la paz se convierte en un significante privilegiado para las autoridades religiosas en su pretensión de habitar el espacio ejemplar en pos de la continuidad del linaje creyente y de la transmisión religiosa institucionalmente validada (Hervieu-Léger, 2010). 


\section{El reino celeste, entre Argentina y Tierra Santa}

Segato (2007) explica que los agentes religiosos son influenciados por las tendencias de la cultura política de una época y que las elecciones entre alternativas internas del campo religioso se articulan en una gramática general que organiza la sociedad y la política para la época (42). La autora clasifica tres actitudes religiosas frente a la transponibilidad o no del territorio, en la cual se articulan los términos de comunidad-ritualidad e iconicidad religiosa y territorialidad: esencialismo del territorio, relativismo de la localidad y territorialidad móvil. Las ideas de la autora permiten el análisis de las prácticas, gestos y discursos de los agentes religiosos en dos dimensiones: en primer lugar, sus nociones sobre las actitudes frente a la transponibilidad del territorio permiten indagar el significado de Tierra Santa para las tres religiones aquí estudiadas, como referente para postular el significante de la paz. Resulta preciso tener en cuenta que las tres actitudes mencionadas se utilizarán como tipo ideal a partir de los dichos de los entrevistados, con el objetivo de generar herramientas para el pensamiento y no creyendo describir una actitud generalizable para la totalidad de las tres religiones monoteístas.

Es importante destacar que en las semanas posteriores a los viajes, el conflicto árabeisraelí en Medio Oriente se intensificó, causando una escala de violencia, muerte y destrucción masivamente difundida por los medios de comunicación internacionales; aun conociendo esta situación, las autoridades religiosas que formaron parte de las actividades inter-religiosas por la paz, las encuentran exitosas y valiosas para el público internacional, y particularmente para la sociedad argentina. En este sentido, la segunda dimensión a estudiar está en relación con la cultura política argentina actual, entendiendo que los viajes inter-religiosos fueron nombrados y entendidos internacionalmente como la "particularidad argentina”. Aun cuando los procesos de diálogo inter-religioso se producen a escala global, los entrevistados resaltan que el proceso en Argentina se encuentra en la vanguardia internacional, lo que pareció legitimarse con el liderazgo del Papa y a través de los viajes en cuestión. De esta manera, las acciones de las autoridades religiosas deben ser pensadas en su relación con la coyuntura argentina, continuando con lo expresado en el apartado anterior en cuanto a la diferenciación entre la ética de virtuosos encarnada en la religión y los intereses económicos e individuales atribuidos a las autoridades políticas. Por último, es preciso llamar la atención sobre la importancia atribuida por todos los entrevistados a la figura del Papa Francisco como líder del proceso dialogal y de las acciones llevadas a cabo en pos de la paz mundial.

"El sionismo es judaismo, la historia del judaismo nace con el primer sionista, Abraham, el primer sionista, el primero que dijo hay que ir a Israel, fue Abraham, un joven iraqui que escuchó a dios diciéndole camina y anda a la tierra que te voy a decir, ¿qué tierra? Canaán, Israel y después siguió en un formato de pueblo donde apareció el segundo sionista, Moisés, una revolución monoteista para llevar a todo el pueblo a Israel, y nuestra vida hace 4.000 
años está cruzada por la tierra de Israel, por nuestra mirada puesta allí, dos mil años de exilio hicieron que todas nuestras festividades terminen con el Ba Shana Ahaba be Birushalaim3. Estamos felices de estar festejando pero el año que viene vamos a hacerlo en Jerusalén, dos mil añosy ese es el sello de la comunidad judía, todos los dias, tres veces por día, se reza y se mira a Jerusalén. No hay rezo, no hay texto, no hay poesía, no hay generación que no haya puesta su corazón en búsqueda a la tierra a la que se dirigió nuestro primer patriarca. (...) El estado de Israel no nace con Hertzl, se materializa con Hertzl el sionismo, pero es la tierra de Moisés, de David, de Salomón, de todos nuestros profetas, en donde se creóy se volvió a recrear unay otra vez el judaísmo histórico" (rabino Alejandro Avruj).

"Kutz, nosotros le decimos kutz pero Jerusalén, Tierra Santa, Kutz, como quieras llamarla, dosfacetas, una la celestial otra la terrenal. La celeste puede expresar la idea del reino del cielo, pero es una cuestión recurrente, si vos a mí me preguntas a mi en términos islámicos ¿qué es lo más sagrado? No, lo más sagrado es la piedra que está en la mezquita porque ahíse apoyó el profeta, ahídespegó hacia el cielo. Y si bajoy le pregunto al rabino que custodia el Muro me va a decir 'el kotel porque es la pared que nos quedó del templo'. Y si le pregunto a un cristiano me va a decir 'el santo sepulcroy la Gólgota o la vía cruxis'y la verdad es que son piedras, son todas piedras (....) y ahora, nosterminamospeleando porpiedras" (dirigenteislámico Omar Abboud).

"La religión cristiana en símisma tiene una relación ambigua con el tema de los lugares porque Jesús dice 'destruyan este temploy en tres díaslo volveréa edificar' (...) No es el mismo apego que tiene la tradición judia, no es el mismo apego que tiene la tradición islámica que es el apego de vivir en un lugar, de echar raices en ese lugar. Nosotros tenemos otra patria, y esa patria es el cielo, entoncessi es en Roma o en Tierra Santa, si los lugares desaparecen será una pena porque es patrimonio histórico, cultural y artístico, pero no pasa nada. Se puede seguir teniendo fey rezando aun sin templos" (cura Guillermo Marcó).

"Para nosotros es Tierra Santa, el corazón de nuestra fe está ahí, es la ciudad donde se deberían plasmar todas estas cosas que hablamos, si tuviéramos que mostrar en quélugar está el corazón denuestras religiones, está en Jerusalem. Ahídeberían hacerse las grandes reuniones, ojalá que en algún momento se pueda. (...) para nosotros los cristianos argentinos, hay lugares santuarios religiosos como Luján, a donde la gente peregrina como aquel judio que iba al templo de Jerusalemy caminaba díaspara llegar, esos lugaresson la Tierra Santa" (padre Pepe DiPaola).

A partir de las entrevistas podemos observar dos actitudes diversas frente a la pregunta por el significado de Tierra Santa, que sin embargo en su diversidad comparten ciertas características. En primer lugar es dable resaltar que para realizar la pregunta se utilizó en todos los casos la palabra "Tierra Santa", y que en todos los casos a la hora de responder los líderes religiosos nombraron al territorio según el modo de hacerlo de su

3. El año que viene en Jerusalén 
religión: Kutz, Canaán, y Tierra Santa. Siendo en este sentido equivalentes, las respuestas distan de serlo a la hora de definir el significado en cuestión. En cuanto a Canaán (Tierra Santa judía) el discurso puede ser incluido al interior de un esencialismo del territorio que torna determinados puntos del paisaje y la tomografía en lugares únicos, que no pueden ser replicados o sustituidos (Segato, 2007:52-53). En los otros dos casos, encontramos en primer lugar la mención a las otras dos religiones monoteístas, tanto Marcó como Abboud dicen que Tierra Santa resulta de carácter inamovible para las otras dos religiones, marcando la diferencia con el caso propio que puede ser caracterizado como una territorialidad móvil sobre un espacio sin marcas, abierto a los tránsitos y a las apropiaciones, en que la marca está en los fieles y en el espacio que ocupan (Segato, 2007: 52-53). En el caso de Di Paola la actitud es la misma aunque resalta el hecho de que también incluye en sus respuestas a las otras dos religiones, y dice que Tierra Santa debiera ser la sede del diálogo. La actitud de territorialidad móvil, hegemónica en la coyuntura actual según Segato, pareciera asociarse en los discursos con una actitud propensa hacia el diálogo y el no-conflicto, mientras que la actitud esencialista, tanto la propia como la atribuida a las otras religiones, dan cuenta de la importancia simbólica que tiene el territorio en cuestión para las tres religiones.

En cuanto a los viajes inter-religiosos a Tierra Santa, los líderes religiosos resaltaron la fuerte relación con la coyuntura argentina actual, polarizada y conflictiva, destinataria de los alcances del diálogo inter-religioso.

"Jamás pensamos que eso iba a tener repercusiones internacionales, pero Bergoglio llegó a ser Papa, entonces esas palabras dichas una tarde en la curia y firmadas, hoy tienen una relevancia, un antecedente de lo que el Papa Francisco viene diciendo a nivel mundial que es No a la violencia" (cura Guillermo Marcó).

"Cuando hicimos (Skorkay Bergoglio) el programa televisivo, el libro, no era solamente para mostrar que unjudio y un católico podemos hablar, podemos entendernos, en lo que diferimos diferimos, sino para mostrar la importancia del diálogo, instalar en una sociedad como la argentina donde falta tanto el diálogo, el concepto de diálogo (...) en la República Argentina podemos decir con mucho orgullo que estamos a la cabeza de esto en el mundo, ahora la sociedad argentina en su totalidad, en todos los aspectos de su existencia, no, el diálogo sigue siendo una dramática materia pendiente, no sabemos dialogar, no sabemos dialogar" (rabino Abraham Skorka).

"No éramos solo dos hombres o tres hombres de distintas religiones, éramos tres argentinos, no éramos una cosa y éramos otra, y dijimos 'bueno, en el modelo de construcción, en todas las groserías que nos pasan en nuestro país tenemos la perspectiva y la visión de que esto es posible' (....) (En cuanto a los alcances) Efectos simbólicos, si vos hablas con una cantidad de público informado, la idea del diálogo inter religioso lo ven como parte de nuestra cultura, particular- 
mente el Instituto es una cos a muy interesante desde el punto de vista de la argentinidad, cuando hicimos el viaje los diarios del mundo que tomaron la noticia, que fueron varios, hablaban del modelo argentino, desde ese lado: bárbaro. Desde el aprendizaje de lo que nosotros queremos tratar de difundir" (dirigente islámico Omar Abboud).

"Si vos pensás, tomás el periodo de 20 años atrás y ves los actos que se han hecho, de las cosas que se han hecho y que incluyen al Papa Francisco por el diálogo inter-religioso, cuando era Arzobispo de Buenos Aires y antes de él estaba Querranchino, un tipo que apostó mucho por el diálogo. El mundo religioso argentino al menos dio un paso importante que creo que ahora desde el Vaticano el Papa puede fortalecer, al menos desde el mundo católico. La sociedad percibe que ha cambiado ya no es más el trato, al menos en Argentina, yo no puedo hablar del mundo pero en la sociedad Argentina ha progresado muchísimo" (padre Pepe Di Paola).

El encuentro religioso en pos de la paz de los líderes religiosos argentinos se opone en todos los discursos a la coyuntura política nacional. El liderazgo del Papa en el plano simbólico parece constituirse antagónicamente con la creciente violencia e hipocresía a escala internacional. Las palabras del mismo "Este diálogo interreligioso es una condición necesaria para la paz en el mundo, y por lo tanto es un deber para los cristianos, así como para otras comunidades religiosas (2013: 189) en la exhortación apostólica Evangelii gaudium, resuenan en cada una de las entrevistas.

"Yo me sentí un testigo de una obra que estaba llevando adelante un hombre, el Papa en particular (...) la del Papa en términos de lenguaje simbólico y en silencio, porque la historia da que en realidad la ceremonia religiosa podría haber sido otra, un discurso, y fue una foto en silencio, de la misma manera cuando el Papa tocó el Muro antes de irnos en la ciudad de Belén o cuando el Papa le besó la mano a un sobreviviente en Iad Ba Ashem, fue en silencio, entonces hay que examinar las secuenciasy analizarlas también en silencio" (dirigente islámico Omar Abboud).

"Esla primera vez que unjudioy un musulmán forman parte oficial dela delegación vaticana en unviaje de peregrinación papal a Tierra Santa, que haya un rabinoy un musulmán es algo inédito en la historiay algo muy especial (...) toda la idea es estar juntos, verse, verse la cara, charlar, ver que el otro es tan humano como uno" (rabino Abraham Skorka).

"Junto con el padre Pepe hicimos un viaje, nosotros dos con cien personas judías y no judías, para acompañar a Francisco en su histórico viaje a Tierra Santay fuimos en acompañamiento, peregrinación y oración, a Jordania, a la autoridad palestina en Belény a su Jerusalén" (rabino Alejandro Avruj). 


\begin{abstract}
"Veamos el caso del Papa Francisco, una persona que es líder de todo el espacio católico y reconocido por la mayoría de los hombres que practican otros credos, otras religiones" (padre Pepe Di Paola).
\end{abstract}

"Para mila pregunta es ¿cuál es la matriz desde donde Francisco piensa todo esto?, y la matrizes esta, él cree en los procesos de paz porque cree que tiene comprobado que las personas aun siendo tan diferentes, o proviniendo de matrices que parecen enfrentarse o ser distintas, en verdad no son tan distintas, tiene claro que los procesos de paz en algún punto vos tenés que enfocarlos con ejemplaridad" (cura Guillermo Marcó).

\title{
Palabras finales
}

El objetivo de esta investigación ha sido el análisis de la función que cumple el significante de la paz en los procesos de diálogo inter-religioso tomando como referente empírico los viajes inter-religiosos realizados por autoridades religiosas argentinas a Tierra Santa y al Vaticano en el año 2014. Entendiendo que las prácticas y los alcances del proceso en cuestión se inscriben en el registro de lo simbólico, se ha presentado un análisis de los discursos producidos por las autoridades religiosas, discursos que hablan sobre gestos que producen efectos y construyen hegemonía. A través de la realización de entrevistas y de la lectura de textos académicos y teológicos, este trabajo demuestra que los participantes de los encuentros, representantes de las tres religiones monoteístas, se inscriben al interior de un proceso de fraternización inter-religioso cuyo punto de partida puede colocarse en la declaración de Nostra Aetate, y fortaleciéndose en los últimos años bajo la figura del Papa Francisco. Este proceso, entendido desde el lugar de sus participantes, da cuenta de la intención de postular al significante de la paz como necesidad ética y moral y de colocar a la religión en un lugar privilegiado de la sociedad civil frente a las coyunturas críticas a nivel global. Se constituye así una frontera en el plano simbólico que diferencia a las autoridades políticas con intereses individuales de las autoridades religiosas a las que se les atribuye una ética de virtuosos.

La realización de esta investigación ha presentado desafíos y límites, entre estos es preciso destacar: la dificultad que implicó la obtención de entrevistas con los máximos referentes de las tres religiones monoteístas en Argentina, acompañantes del Papa Francisco en los viajes a Tierra Santa, lo cual precisó de una gran cantidad de tiempo y capital social para lograr el alcance y los encuentros con los entrevistados; el esfuerzo perpetuo, a la hora de la lectura de fuentes religiosas y teológicas producidas por los agentes cuyos discursos constituían la unidad de observación de esta investigación, para evitar caer en un proceso de triple hermenéutica, explicado por Vasilachis de Gialdino (2006) como: el proceso que se produce cuando los investigadores utilizan en su análisis modelos interpretativos "vigentes en discursos enraizados en la situaciones de poder, 
y que tienden a conservarlas", llevando así a una reproducción de los discursos dominantes y de las posiciones que los producen y sostienen (48); por último la complicada tarea de hallar análisis académicos en torno a procesos de nuestra historia reciente. Se espera haber realizado una investigación fructífera para el desarrollo del análisis de un proceso que es actual, política y social, allanando el campo para futuras contribuciones.

\section{Referencias}

ALONSO, A. (2008). "Exclusión y diálogo en la confrontación de hegemonías. Notas sobre la relocalización de influencias en el campo religioso latinoamericano", en Alonso, A. (comp.): América Latina y el Caribe. Territorios religiosos y desafíos para el diálogo. Buenos Aires: CLACSO.

BERGER, P. (1968). El dosel sagrado. Buenos Aires: Amorrortu.

BOURDIEU, P. (1993). “La disolución de lo religioso” en Cosas dichas. Barcelona: Gedisa.

BOURDIEU, P. y DE SAINT MARTIN, M. (2009). "La sagrada familia. El episcopado francés en el campo del poder”, en Bourdieu, P. La eficacia simbólica. Religión y política. Buenos Aires: Biblios.

CASANOVA, J. (1999). “Religiones públicas y privadas”, en Auyero, J. Caja de herramientas. El lugar de la cultura en la sociología norteamericana. Buenos Aires: UNQ.

CORRAL, S. y PETSCHEN VERDAGUER, S. (2005). "El diálogo religioso", en UNISCI Discussion Papers, Mayo: 1-24.

EXHORTACIÓN APOSTÓLICA, Evangelii gaudium redactada por el Papa Francisco (2013) disponible en https://www.aciprensa.com/Docum/evangeliigaudium.pdf

FORNI, F. (1993). “Estrategias de recolección y estrategias de análisis en investigación social”, en Forni; Gallart; Vasilachis, Métodos cualitativos. Buenos Aires: Centro Editor de América Latina.

GARMA, C. (2011). "Laicidad, Secularización y Pluralismo religioso, una herencia cuestionada" en Revista del Centro de Investigación, Julio-Diciembre, 79-92.

GEERTZ, C. (1997). La interpretación de las culturas. Barcelona: Gedisa.

GALABERT BALLESTER, M. (2006). “Las religiones, inspiradoras de humanización”. Veritas. Revista de Filosofía y Teología, (34), 143-157.

HERVIEU-LÉGER, D. (2008). "Producciones religiosas de la modernidad", en Mallimaci, F. (comp.) Modernidad, religión y memoria. Buenos Aires: Colihue.

HERVIEU-LÉGER, D. (1996). "Catolicismo. El desafío de la memoria”. Sociedady Religión, (14/15).

KEPEL, G. (1991). La revancha de Dios. Madrid: Anaya.

LACLAU, E. (2005). La Razón Populista. Buenos Aires: FCE. 
LACLAU, E. y MOUFFE, C. (2006). Hegemonía y Estrategia Socialista. Buenos Aires: FCE.

MALLIMACI, F. (2013). "El catolicismo argentino de Bergoglio y el papado de Francisco: Una primera aproximación desde la Argentina". Sociedad y Religión (40), 211-244.

MORALES, B. y LAURENCE, J. (2011). "Teología del Pluralismo Religioso: paradigma y frontera”. Franciscanum. Revista de las ciencias del espíritu, (53), 75-104.

ORTIZ, R. (2005). “Religión y globalización”, en Mundialización: saberes y creencias. Barcelona, España: Gedisa.

PACE, E. (2013). "El papa Francisco frente a la crisis sistémica de la iglesia una, santa, católica y romana”. Sociedad y Religión, (40), 247-271.

PIERUCCI, A. F. (1998). “Soltando amarras: secularización y destradicionalización”. Sociedad y religión, (16/17), 101- 131.

ROGERS F. J. (2012). "Universale Salutis Sacramentum: la Iglesia como sacramento universal de salvación en relación con los desafíos del diálogo interreligioso". Revista Iberoamericana de Teología, (8), 25-47. http://www.ceil-piette.gov.ar/docpub/revistas/sociedadyreligion/sr16-17/sr1617pierucci.pdf

SEGATO, R. L. (2007). "La faccionalización de la república y del paisaje religioso como índice de una nueva territorialidad", en Alonso, A. (comp.), América Latina y el Caribe: territorios religiosos y desafíos para el diálogo. Buenos Aires: CLACSO.

SCOBAR SORIANO, J. D. (2006). “Teología de las religiones y diálogo interreligioso”. Veritas. Revista de Filosofía y Teología, (15), 43-57.

SETTON, D. (2002). "Experiencia identitaria y reproducción de la autoridad en el judaísmo ortodoxo". Sociedady Religión, (24/25), 7-18.

ULLOA RUBKE, G. (2008). "El digo interreligioso: pasado, presente y futuro". Veritas. Revista de Filosofía y Teología, (19), 371-382.

VASILACHIS DE GIALDINO, I. (2006): Estrategias de investigación cualitativa. Barcelona: Gedisa.

VILLAR, J. R. (2001). "La Iglesia, el ecumenismo y las religiones no cristianas". Anuario de Historia de la Iglesia, 225-238.

WEBER, M. (1964). "Los caminos de la redención y su influencia en el modo de vida”, en Economía y Sociedad. México: FCE. 